\title{
Protective Effect of Ascorbic Acid and Ranitidine on the Indomethacin Induced Gastric Injury in Adult Albino Rats; Light and Electron Microscopy
}

\author{
Saadia Ahmed Shalaby, Essam Mohamed Eid, Osama Fouad Ahmed*, Marim Fayz Abdow \\ Department of Anatomy, Faculty of Medicine, Benha University, Benha City, Egypt
}

Email address:

osamafouad20@yahoo.com (O.F. Ahmed)

To cite this article:

Saadia Ahmed Shalaby, Essam Mohamed Eid, Osama Fouad Ahmed, Marim Fayz Abdow. Protective Effect of Ascorbic Acid and Ranitidine on the Indomethacin Induced Gastric Injury in Adult Albino Rats; Light and Electron Microscopy. International Journal of Clinical and Developmental Anatomy. Vol. 2, No. 1, 2016, pp. 1-13. doi: 10.11648/j.ijcda.20160201.11

\begin{abstract}
Indomethacin is a non-steroidal anti-inflammatory drug, used in the treatment of many inflammatory diseases. The major side effect limiting its clinical use is the gastric damages. The aim of this work was to study the possible protective effects of vitamin $\mathrm{c}$ and ranitidine on the gastric lesion induced by indomethacin in adult albino rats. Forty adult albino rats were divided into five equal groups: The control group, indomethacin group, indomethacin plus vitamin c, indomethacin plus ranitidine, and indomethacin plus both vitamin $\mathrm{c}$ and ranitidine. In the control group, the rats received normal daily diet for 10 days. In the indomethacin group, the rats were treated with indomethacin for 10 consecutive days. In indomethacin plus vitamin $\mathrm{c}$ group, the rats were treated with indomethacin as the second group, in addition to vitamin c, 5 minutes prior to the indomethacin for 10 days. In the fourth group, the rats were treated with indomethacin as the second group, and then received ranitidine $5 \mathrm{~min}$ prior to the indomethacin, for 10 consecutive days. The last group received the indomethacin as the second group, and then received vitamin $\mathrm{c}$ and ranitidine, $5 \mathrm{~min}$ prior to the indomethacin, daily for 10 days. After 10 days from the treatment, all the rats were anaesthetized, and the specimens of the stomach were prepared for light and electron microscopies. Indomethacin produced erosions and ulcerations of the gastric mucosa. There are focal areas of degeneration and inflammatory cell infiltration in the lamina propria, the gastric gland cells showed vacuolations, degeneration and disappearance of their nuclei. It also induced dilatation and congestion of the blood capillaries in the submucosa of the stomach, also the surface mucin layer was decreased in its thickness. Electron microscopic examination showed that: Indomethacin induced degeneration and vacuolations of the gastric gland cells, with degeneration of their mitochondria and nuclei. Chief cells showed abnormalities in their zymogenic granules which appeared with dark central part and pale periphery. Administration of vitamin $\mathrm{c}$ and ranitidine prior to the indomethacin intake reduced the pathogenic changes of the gastric wall, with slight return to the picture of the control group.
\end{abstract}

Keywords: Indomethacin, Ascorbic Acid Gastroprotective Effect, Antioxidant Enzymes

\section{Introduction}

Indomethacin is an indol derivative, non- steroidal, antiinflammatory drug with an analgesic and antipyretic effects [1] as regard the gastrointestinal tract, indomethacin might cause nausea, vomiting, dyspepsia, gastro-intestinal lesions. Serious reactions, including gastro-intestinal bleeding, ulceration, and perforation in patients receiving indomethacin [2].

Recent studies have suggested that, the indomethacin performs pre-oxidant activity and initiate lipid peroxidation by generation of reactive oxygen species (Ros) that play a critical role in gastric ulcer formation [3 \& 4]. [5] Studied the protective effect of ascorbic acid against gastric mucosal damage induced by indomethacin. They found that ascorbic acid is a powerful antioxidant because it can donate a hydrogen atom forming a relatively stable ascorbyl free radicle. Ascorbic acid is one of the anti-oxidant enzymes, that can decrease the effect of (Ros) and nitrogen species that can cause oxidative damage to gastric mucosa [6].

Ranitidine is a histamine H2- receptor antagonist that inhibits stomach acid production so; it may play a role in the adverse of bad effect of indomethacin on stomach mucosa [7]. The aim of this work is to study the structural changes of the gastric mucosa of adult albino rats after administration of; 
indomethacin group, indomethacin group treated with vitamin c, indomethacin group treated with ranitidine and indomethacin group treated with both ascorbic acid and ranitidine.

\section{Materials and Methods}

Indomethacin (Indocid capsule $25 \mathrm{mg}$ ), It was obtained from Cairo Pharco Chemical Company, Ascorbic acid (vitamin C), It was obtained from El-Gomhoria chemical company in the form of white powder soluble in water, Ranitidine (Zantac tablet, 150mg), it was obtained from Cairo Pharco Chemical Company. Forty adult albino rats were used in this work. Their weight ranged from 200-250 g. They were divided into five groups. Each group was consisted of eight rats; each two rats were housed in a separate plastic cage, at room temperature. They were fed balanced diet consisted of milk, vegetables and bread. All rats were kept under the same circumstances throughout the experiment.

The forty adult albino rats were divided into 5 groups. Each group consisted of eight rats: Group I. (control group), they received normal daily diet for 10 days. Group II. (Indomethacin group), they were treated with indomethacin $(25 \mathrm{mg} / \mathrm{kg}$ body weight) by gastric tube for 10 days. Group III. (Indomethacin group treated with vitamin C), they were treated with indomethacin in a dose $(25 \mathrm{mg} / \mathrm{kg}$ body weight/day). Then with vitamin $\mathrm{C}$ in dose $(400 \mathrm{mg} / \mathrm{kg}$ body weight) orally by gastric tube, 5 min prior to indomethacin intake for 10 days. Group IV. (Indomethacin group treated with ranitidine), they were treated with indomethacin in a dose ( $25 \mathrm{mg}$ body weight/day). Then with ranitidine (25 $\mathrm{mg} / \mathrm{kg}$ body weight) orally by gastric tube, $5 \mathrm{~min}$ prior to indomethacin intake. Group V. (Indomethacin group treated with both ascorbic acid and ranitidine), they were treated with indomethacin in a dose $(25 \mathrm{mg} / \mathrm{kg}$ body weight/day). Then with ascorbic acid and ranitidine with the same previous dose, $5 \mathrm{~min}$ prior to indomethacin intake for 10 days. After 10 days of treatment, all rats were anaesthetized using ether inhalation and the abdomen was opened by midline incision, and the stomach was removed. The specimens were taken from the fundus of the stomach, were prepared for light microscopic analysis using Hematoxylin and Eosin (Hx \& E) stain and Periodic Acid Schiff (PAS) stain. Other specimens of the gastric mucosa were prepared for electron microscopic analysis.

\section{Results}

\subsection{Control Group}

By light microscopy, the histological structure of the stomach wall of the control group showed that: It is formed of mucosa, submucosa, muscle layer; the mucosa is separated from the submucosa by a layer of smooth muscle muscuolaris mucosae. The mucosa consists of surface epithelium that invaginates forming the gastric pits. It contains branched and tubular glands, which extend from the muscularis mucosae throughout the length of the mucosa, with blood capillaries in the mucosa and the submucosa [Figs $1 \& 2]$.

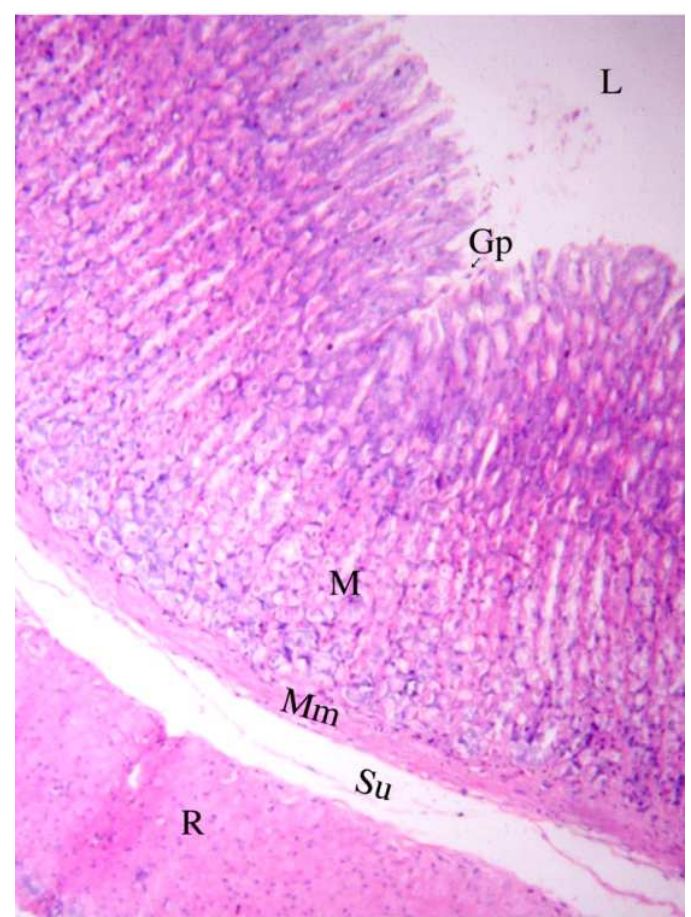

Fig. 1. A light photomicrograph of an adult control rat fundic stomach showing: The gastric mucosa (M), lamina propria, muscularis mucosae $(\mathrm{Mm})$, submucosa (Su), and the gastric muscle layer $(\mathrm{R})$. Notice, the lumen of the stomach (L), and the gastric pit $(G p)$. ( $H X \& E x 40)$.

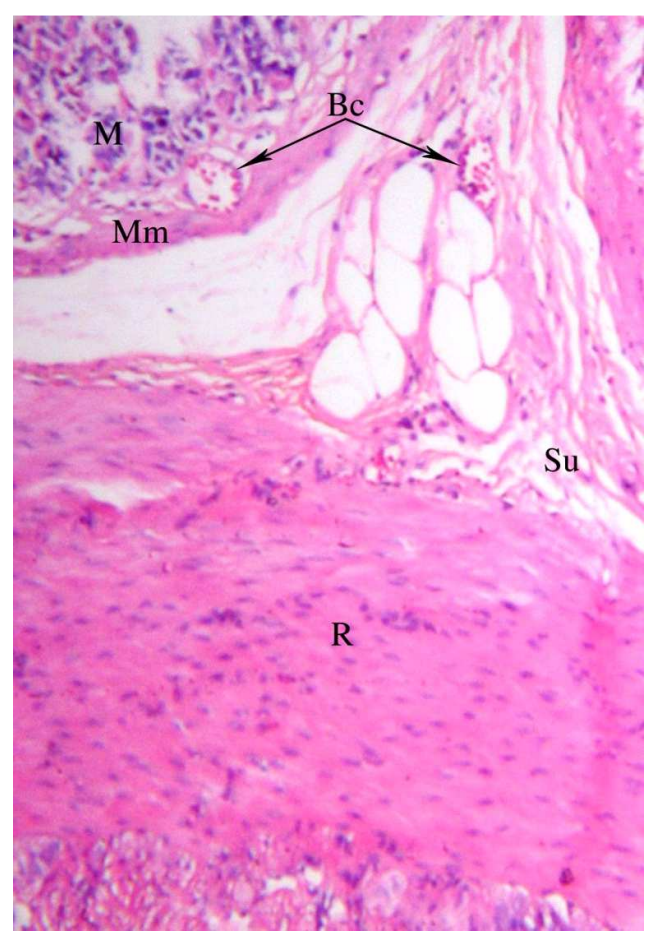

Fig. 2. A light photomicrograph of an adult control rat fundic stomach showing: Intact blood capillaries (Bc) in the gastric mucosa (M) and in the submucosa (Su). Notice the muscuolaris mucosae (Mm), and the gastric muscle layer (R). (HX\& E X100). 
The gastric glands consist of a mixed population of cells; Parietal cells, which appear spherical with central deeply stained nucleus and eosinophilic cytoplasm, and are distributed through the length of the glands particularly in its upper half [Figs 3, 4 \& 5]. Chief cells (Zymogenic cells); Appear as pyramidal cell with deeply stained basal rounded nucleus, located between the parietal cells and predominate in the lower part of the tubular glands [Figs 3 \& 4 ]. Neuroendocrine cells; Appear as rounded cells with vesicular nucleus and clear cytoplasm, located between the parietal cells in the base and the neck of the gland [Figs 4 \& 5]. P. A. S. Stain of the gastric mucosa showed the surface mucous cells, were covered with mucin, which appeared as thick layer and purple in colour [Figs $6 \& 7$ ].

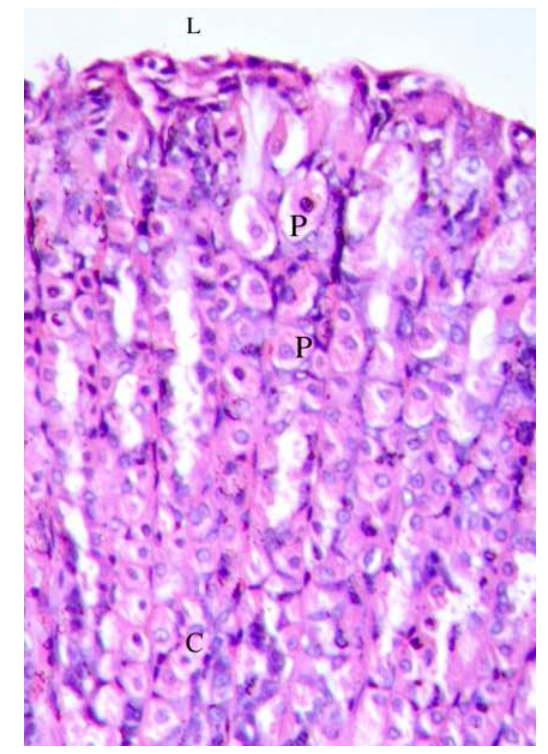

Fig. 3. A light photomicrograph of an adult control rat fundic stomach showing: Normal gastric mucosa with intact parietal cells $(P)$, which is spherical cell with central deeply stained nucleus and eosinophilic cytoplasm. The chief cells $(C)$ are pyramidal in shape with basal nucleus and eosinophilic cytoplasm. Notice the lumen of the stomach (L). (Hx \& E X200).

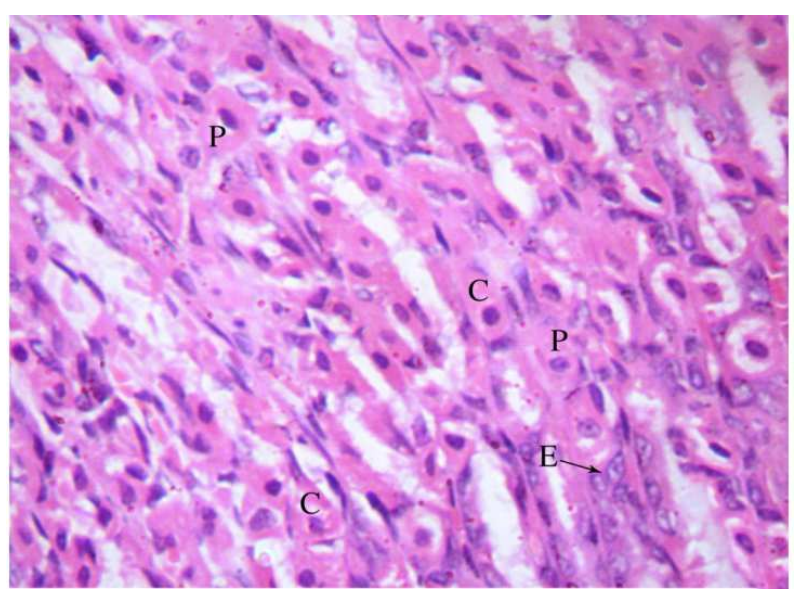

Fig. 4. A higher magnification of the previous section showing: Normal gastric mucosa containing intact gastric gland cells, parietal cells $(P)$ which are spherical cell with deeply stained dark nucleus and eosinophilic cytoplasm, chief cells (C) which are pyramidal cell with basal nucleus and eosinophilic cytoplasm, and neuroendocrine cells (E) which are rounded cells with vesicular nucleus. (Hx \& E X400).

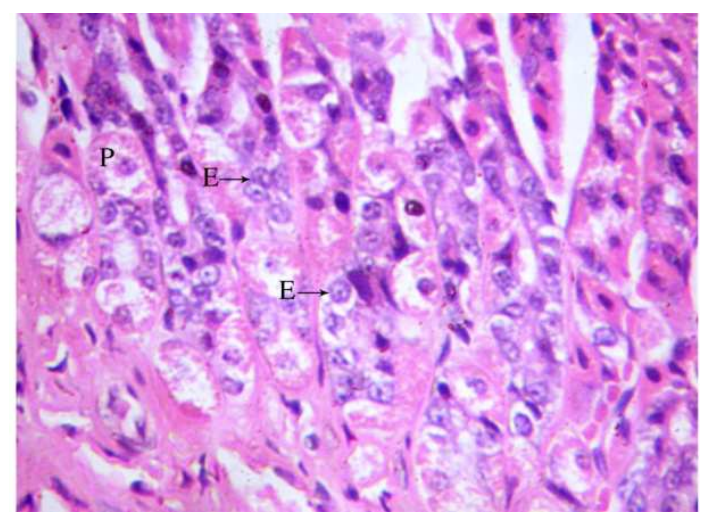

Fig. 5. A light photomicrograph of an adult control rat fundic stomach showing: Normal gastric mucosa containing intact gastric gland cells, parietal cells $(P)$ which are spherical cell with central deeply stained nucleus and eosinophilic cytoplasm, and neuroendocrine cells (E) which are rounded cell with vesicular nucleus and pale cytoplasm.(Hx \& E X400).

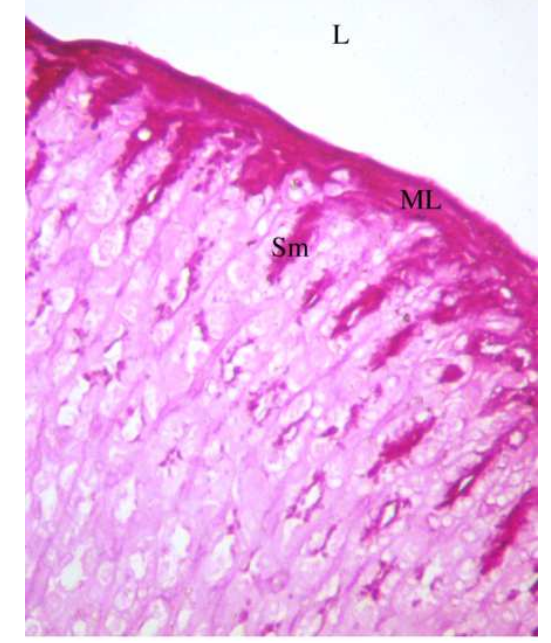

Fig. 6. A light photomicrograph of an adult control rat stomach showing: Normal gastric mucosa with thick surface mucin layer (ML) and intact surface mucous cells (Sm). Notice, the lumen of the stomach (L). (P.A.S X200).

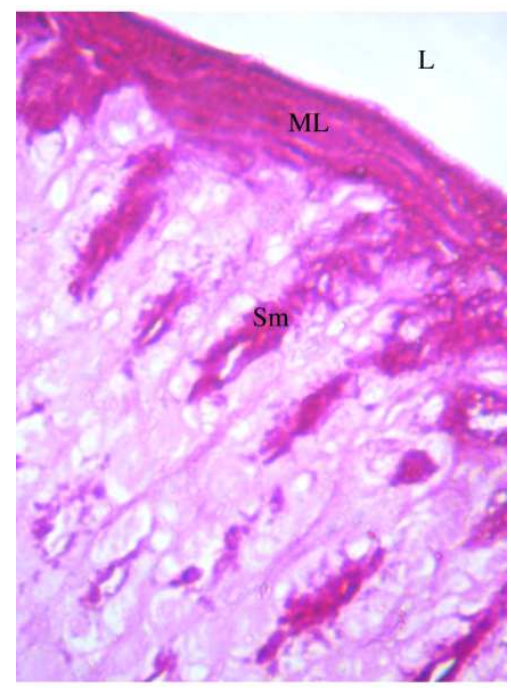

Fig. 7. A light photomicrograph of the previous section showing: Normal gastric mucosa with thick surface mucin layer (ML) and intact surface mucous cells (Sm). Notice, the lumen of the stomach (L). (P. A. S X 400). 
By electron microscopy, the parietal cells have central, regular and rounded nucleus with nucleolus, the cytoplasm has large number of mitochondria, and there are a characteristic intracellular canaliculi with microvilli [Figs 8 $\& 9$ ]. It also contains many mitochondria with their cristae, around its nucleus (Fig 10). The chief cells have a basal, rounded nucleus with nucleolus, its cytoplasm contains a number of mitochondria and large number of zymogenic granules and extensive rER. The mucus secreting cells, lying mainly near the lumen, contain characteristic secretory granules and basal nucleus with irregular nuclear membrane [Figs 11, 12 \& 13].

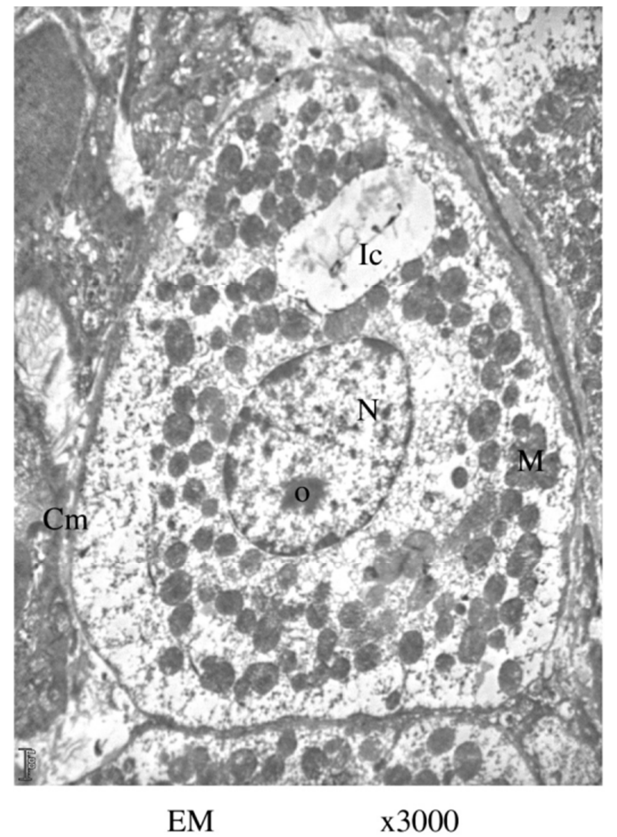

Fig. 8. An electron micrograph of an adult control rat fundic mucosa showing: Intact parietal cell which has rounded, central and regular nucleus $(N)$ with its nucleolus $(O)$, regular cell membrane $(C m)$, large number of mitochondria (M), and characteristic intracellular canaliculi (Ic). (E. MX 3000).

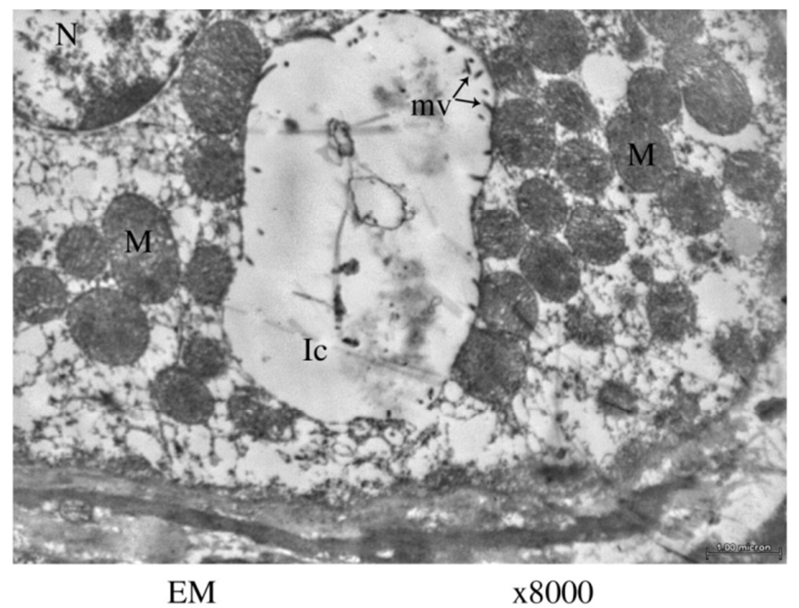

Fig. 9. A higher magnification of the previous section showing: Intracellular canalliculi (IC), which is surrounded by large number of mitochondria (M) inside the cytoplasm of the parietal cell. Notice, the microvilli I (mv) projecting in the canaliculi, and a part of the nucleus of the cell (N). (E. MX 8000).

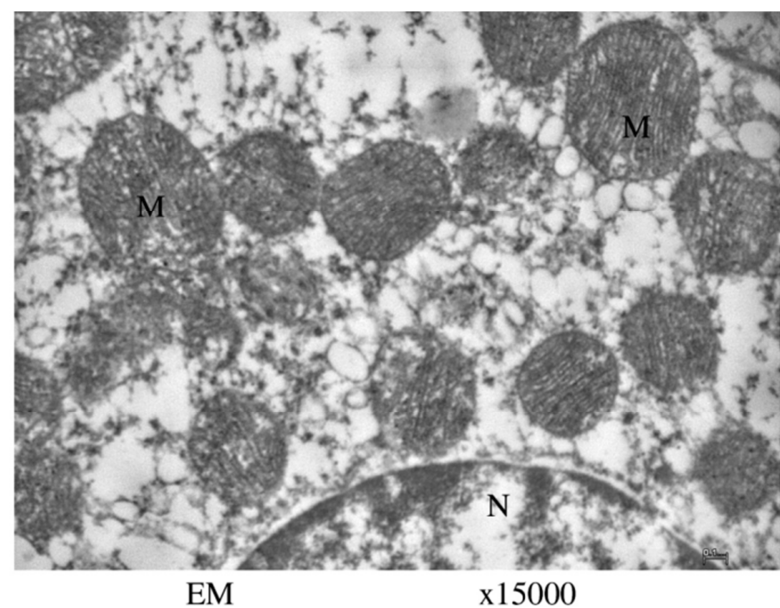

Fig. 10. A higher magnification of figure (9) showing: Large number of mitochondria $(M)$ around the nucleus $(N)$ of the parietal cell. Notice, the cristae inside the mitochondria. (E. MX15000).

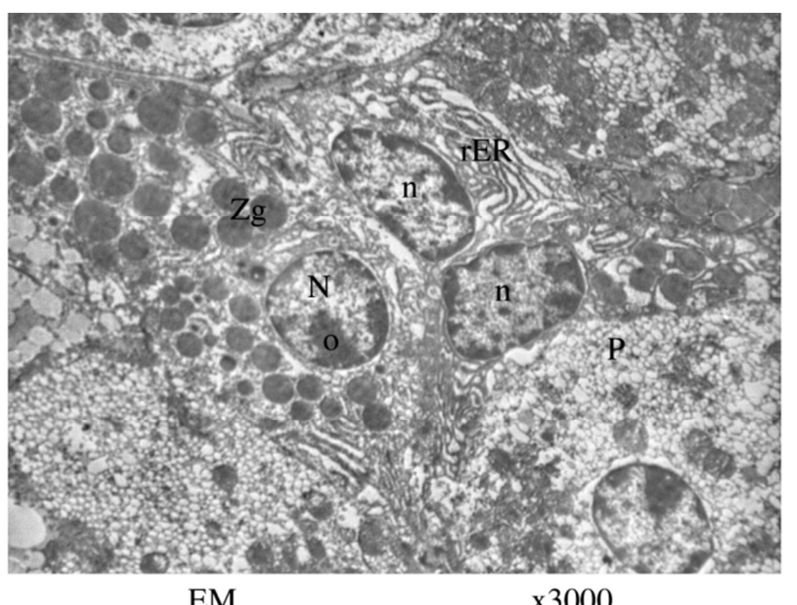

Fig. 11. An electron micrograph of an adult control rat fundic mucosa showing: Intact chief cell which is pyramidal in shape with basal rounded nucleus $(N)$ and nucleolus $(O)$. The apical part of the cell contains a large number of zymogenic granules (Zg). Also, notice, the adjacent normal chief cell has double nuclei ( $n)$, close to it the rough endoplasmic reticulum ( $r E R)$. Also, there is intact neighboring parietal cell (P). (E. M X 3000).

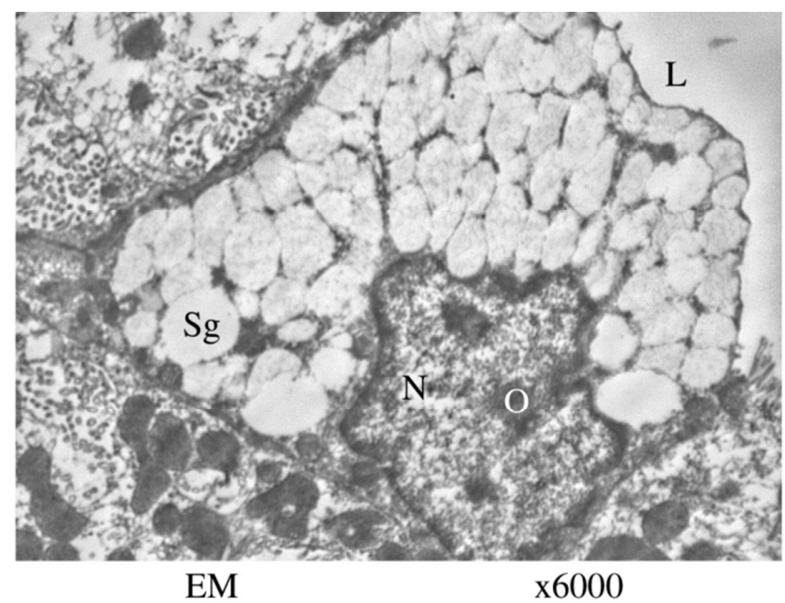

Fig. 12. An electron micrograph of an adult control rat fundic mucosa showing: Intact surface mucous cell lining the lumen of the stomach (L), it has rounded secretory mucin granules (Sg). Notice, the nuclei (N) with irregular nuclear membrane and nucleolus (O). (E. MX 6000). 


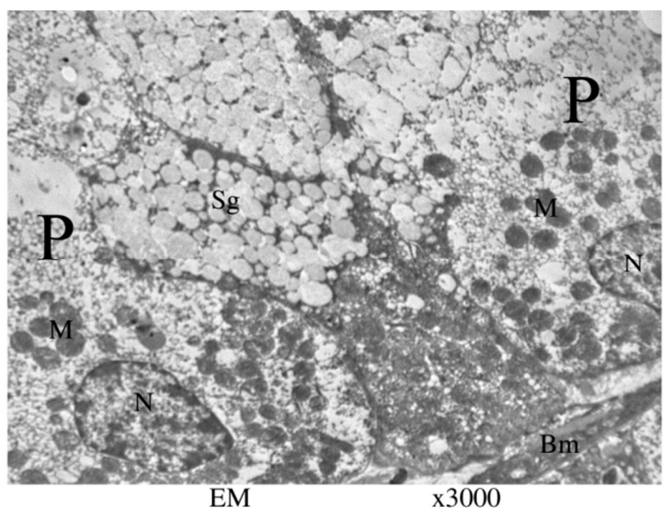

Fig. 13. An electron micrograph of an adult control rat gastric mucosa showing: Two intact parietal cells $(P)$, having many mitochondria $(M)$ and rounded nucleus $(N)$. Notice, normal mucous secreting cell containing secretory granules (Sg), in between them. (E. MX 3000).

\subsection{Indomethacin Group}

By light microscopy, there are areas of erosion of the gastric mucosa, the muscuolaris mucosae becomes exposed to the lumen of the stomach [Fig. 14]. The gastric gland cells show vacuolations and degeneration, with disappearance of their nuclei and cytoplasm [Figs 15, 16 \& 17]. There is dilatation and congestion of the blood capillaries in the submucosa [Fig. 18]. Some areas in the gastric mucosa show focal areas of degeneration and infiltration of inflammatory cells in its lamina propria [Figs $19 \& 20]$. P. A. S. stain of the gastric mucosa showed thin surface mucin layer, with depletion of PAS stained granules, denoting degeneration of the surface mucous cells [Fig. 21].

By electron microscopy, the parietal cells show degeneration of nucleus and mitochondria (Figs 22 \& 23). The chief cells contain dispersed endoplasmic reticulum, basal pyknotic and irregular nucleus, its zymogenic granules appeared intermingled with vacuolations. It has a dark central part with pale periphery [Figs $24 \& 25]$.

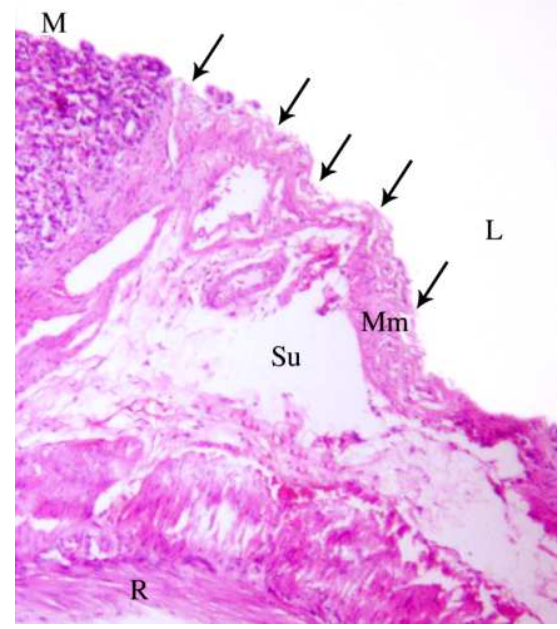

Fig. 14. A light photomicrograph of an adult rat stomach treated with indomethacin showing: Eroded gastric mucosa (arrows), the muscularis mucosae (Mm) is exposed to the lumen $(L)$ of the stomach. Notice, intact gastric mucosa (M) in the upper left side of the photo, submucosa (Su), and the gastric muscle layer (R). (HX \& E X100).

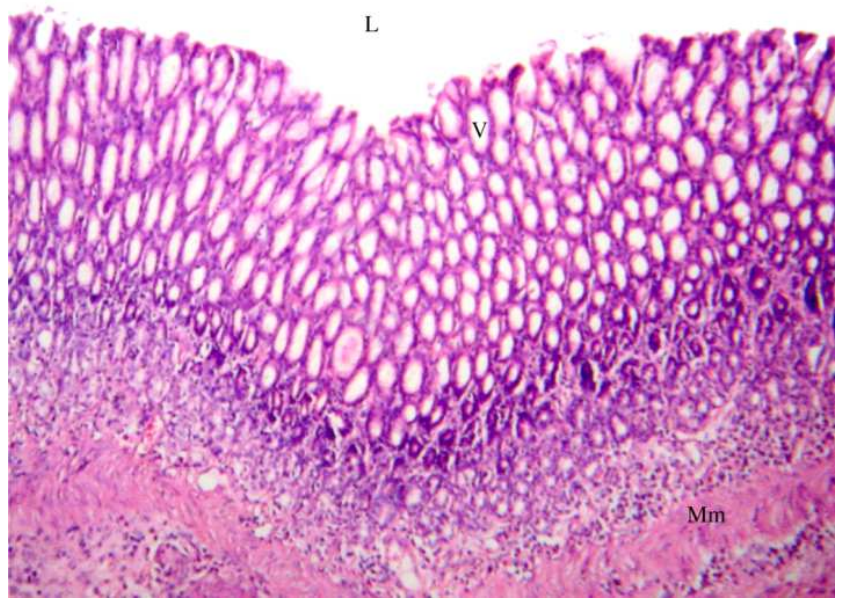

Fig. 15. A light photomicrograph of an adult rat fundic stomach treated with indomethacin showing: The surface gastric mucosa having marked vacuolations $(V)$ of the gastric gland cells. Notice, intact muscuolaris mucosa (Mm), lamina propria, and the lumen of the stomach $(L)$. (HX\&E X100).

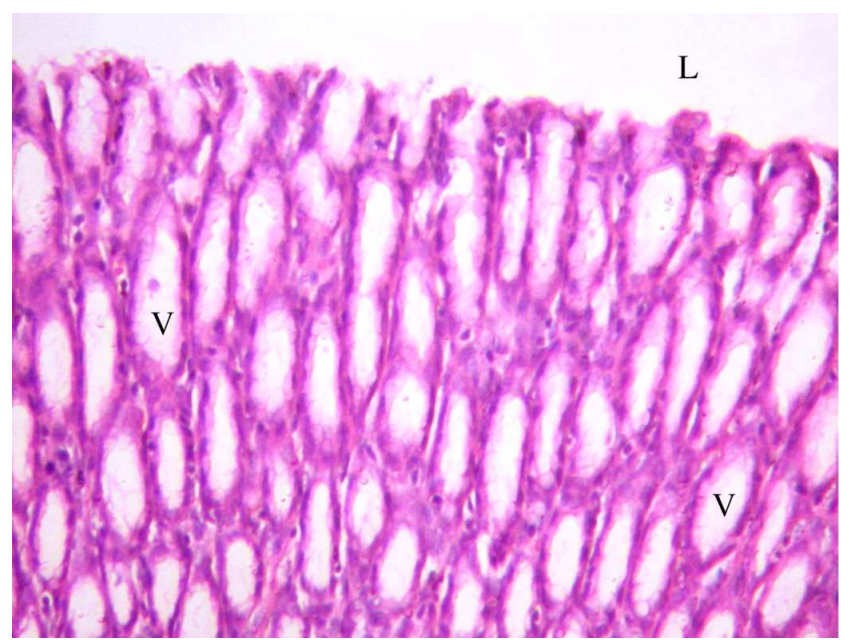

Fig. 16. A higher magnification of the previous section showing: The surface gastric mucosa with marked vacuolations (V) of the gastric gland cells. Notice, the lumen of the stomach (L). (HX\&EX200).

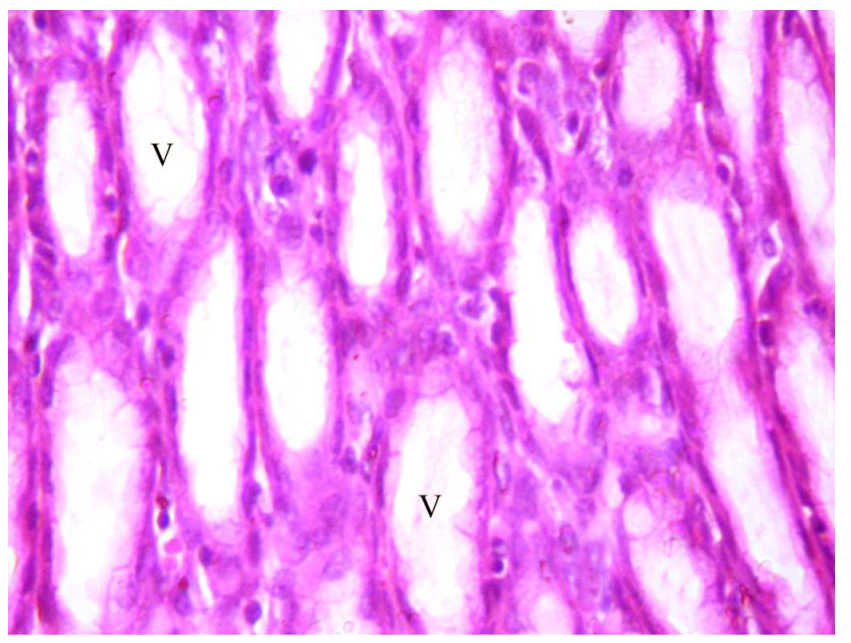

Fig. 17. A higher magnification of the previous section showing: Degenerated gastric mucosa with marked vacuolations $(V)$ of the gastric gland cells. (Hx \& E X400). 


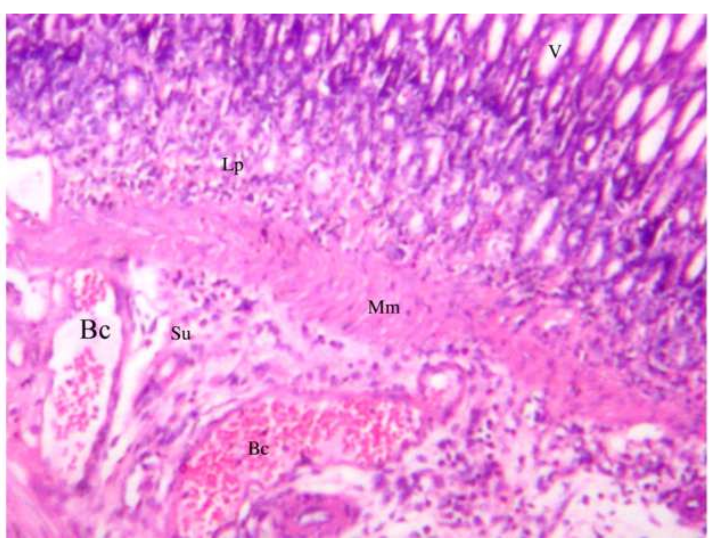

Fig. 18. A light photomicrograph of an adult rat fundic stomach treated with indomethacin showing: Congestion of the blood capillaries (Bc) in the submucosa (Su). Notice vacuolated gastric gland cells (V) in the gastric mucosa. Notice the lamina propria (Lp), and the muscuolaris mucosae $(\mathrm{Mm}) .(H x \& E X 100)$.

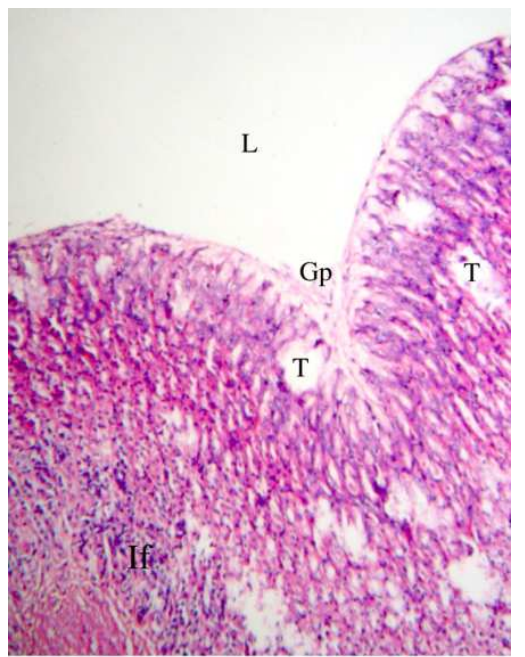

Fig. 19. A light photomicrograph of an adult rat fundic stomach treated with indomethacin showing: Focal areas of degeneration of gastric mucosa (T) with infiltration of inflammatory cells (If). Notice, the gastric pit (Gp) and the lumen (L). (Hx \& EX100).

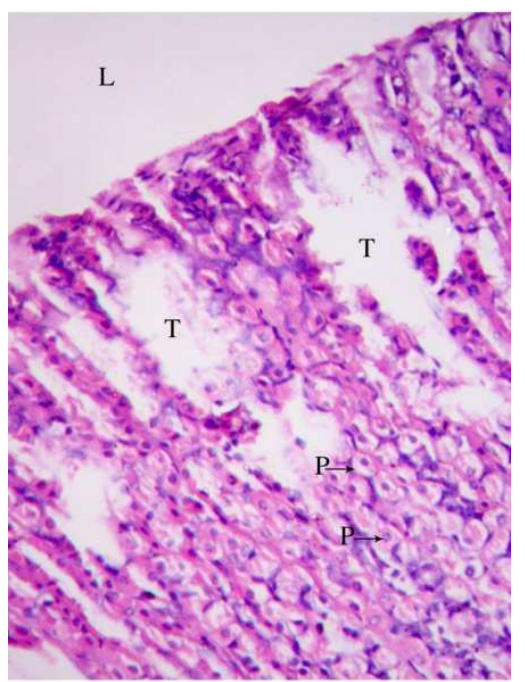

Fig. 20. A higher magnification of the previous section showing: Areas of focal degeneration (T) in the gastric mucosa. Notice, other areas of intact parietal cells $(P)$ and the lumen of the stomach (L). (Hx \& E X200).

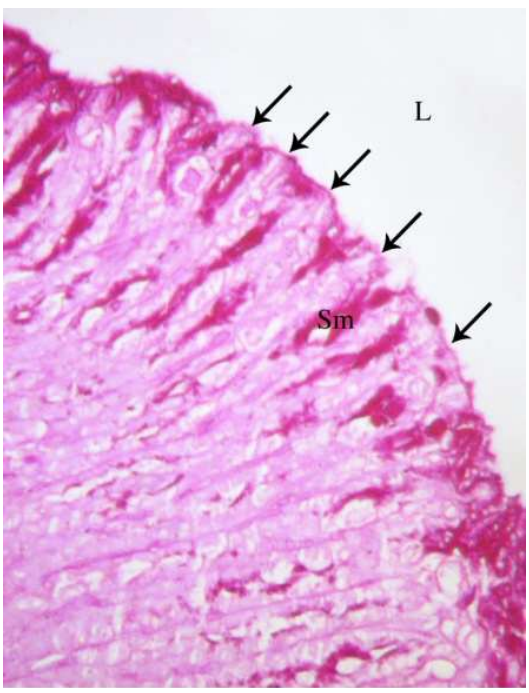

Fig. 21. A light photomicrograph of an adult rat fundic stomach treated with indomethacin showing: The gastric mucosa with thin surface mucin layer (arrows). Notice, the depletion in the number of the surface mucous cells (Sm). (P. A. S. X 200).

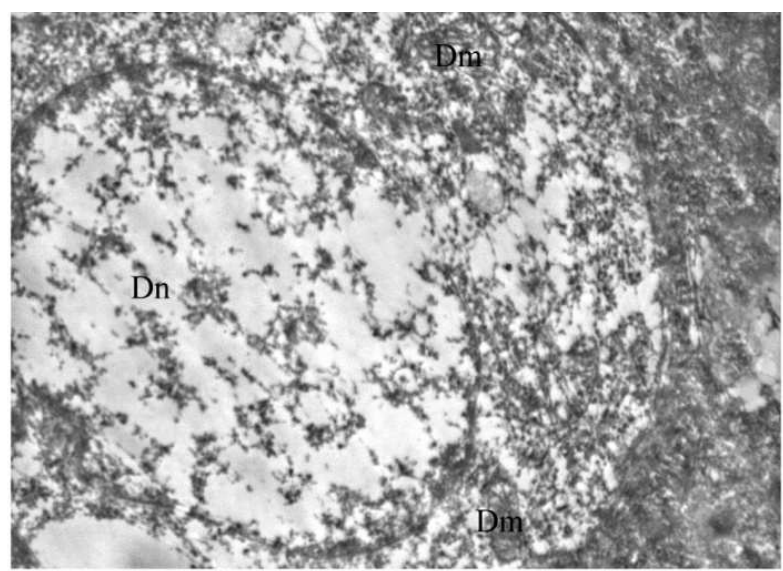

EM

x8000

Fig. 22. An electron micrograph of an adult rat fundic mucosa treated with indomethacin showing: The parietal cell having degenerated nucleus (Dn), and degenerated mitochondria (Dm). (E. MX 8000).

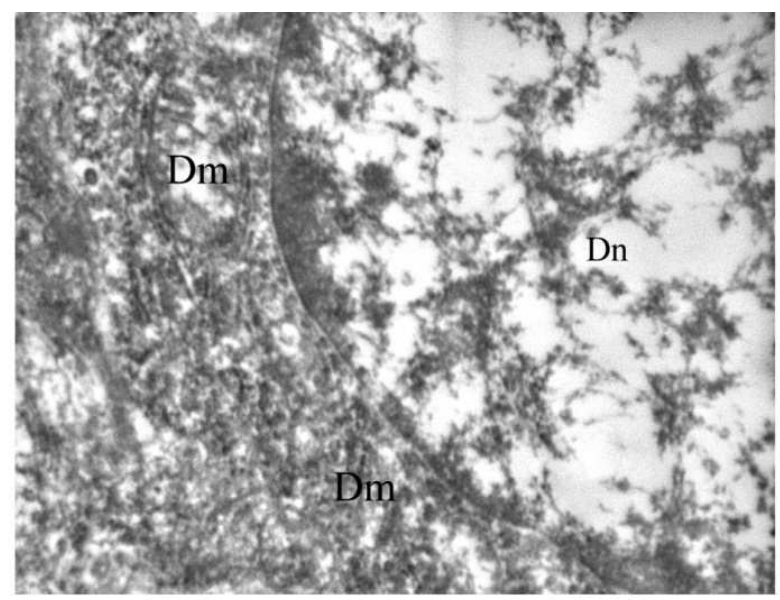

$$
\text { EM } \quad \mathrm{x} 15000
$$

Fig. 23. A higher magnification of the previous section showing: Degeneration of the mitochondria (Dm) and the nucleus of (Dn) the parietal cell. (E. MX 15000). 


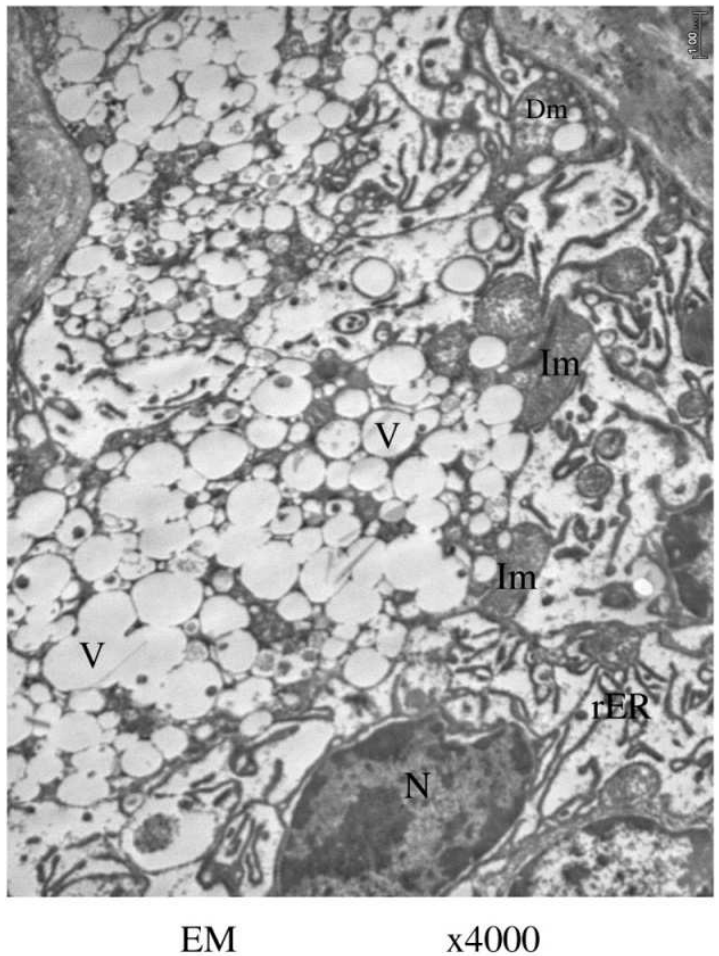

Fig. 24. An electron micrograph of an adult rat fundic mucosa treated with indomethacin showing: Many vacuoles $(V)$ in the cytoplasm of the chief cell. Notice, small basal pyknotic nucleus (N), some mitochondria are degenerated (Dm), while others are intact (Im), and dispersed rough endoplasmic reticulum (rER) in between the vacuoles. (E. MX 4000).

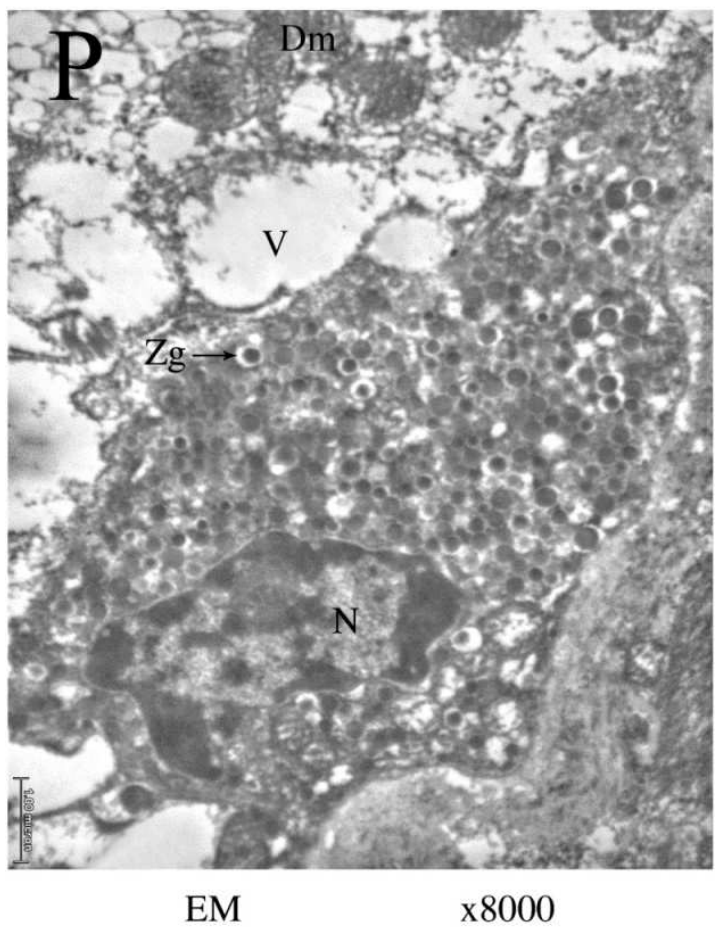

Fig. 25. An electron micrograph of an adult rat fundic mucosa treated with indomethacin showing: partial degeneration of zymogenic granules ( $\mathrm{Zg}$ ) of the chief cell having deeper central part and pale periphery. Notice, large vacuoles $(V)$ and degenerated mitochondria (Dm) in the neighbouring parietal cell $(P)$, and pyknotic heterochromatic nucleus $(N)$ of the chief cell. (E. $M X 8000)$.

\subsection{Indomethacin Group Treated with Ascorbic Acid}

By light microscopy, parietal cells, chief cells and mucous secreting cells show partial regeneration, some cells was intact, while others was vacuolated and degenerated [Figs. 26 $\&$ 27]. Another area showed congestion of the submucosal blood capillaries with intact some parietal cells [Fig. 28]. P. A. S. stain of the gastric mucosa showed thin layer of mucin secretion on the surface of the gastric mucosa when compared with the control group, other areas not covered with mucin [Fig. 29].

By electron microscopy, parietal cells show partial regeneration, it have intact nucleus and some intact mitochondria, while other mitochondria are degenerated. The cytoplasm contained some vacuoles [Fig 30]. Chief cell had started to regenerate, where it has translucent zymogenic granules, with partial reappearance of its normal shaped nucleus and nucleolus [Fig. 31].

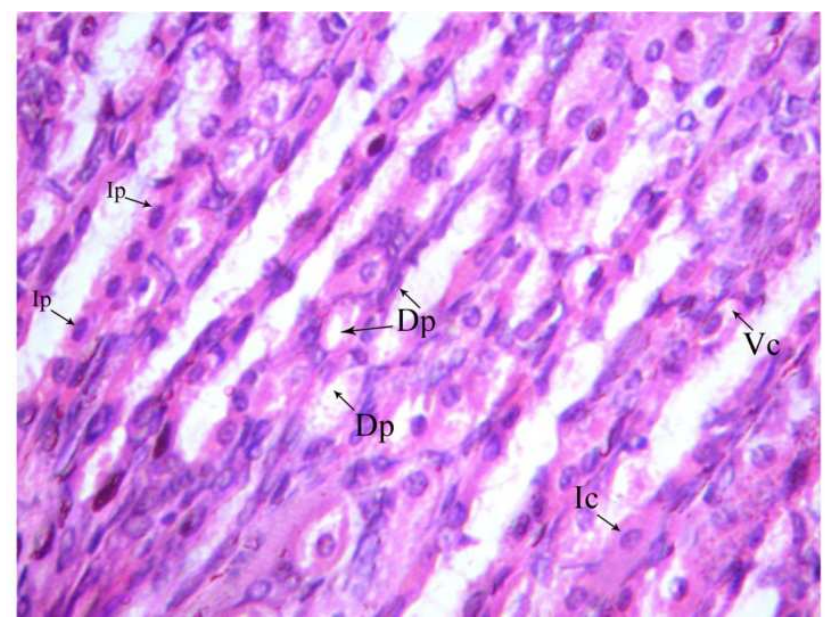

Fig. 26. A light photomicrograph of an adult rat fundic stomach treated with indomethacin and ascorbic acid, showing: Some parietal cells are intact (Ip), while others are degenerated (Dp). Some chief cells are intact (Ic), while others are vacuolated $(V c)$. ( $H x \& E$ X200).

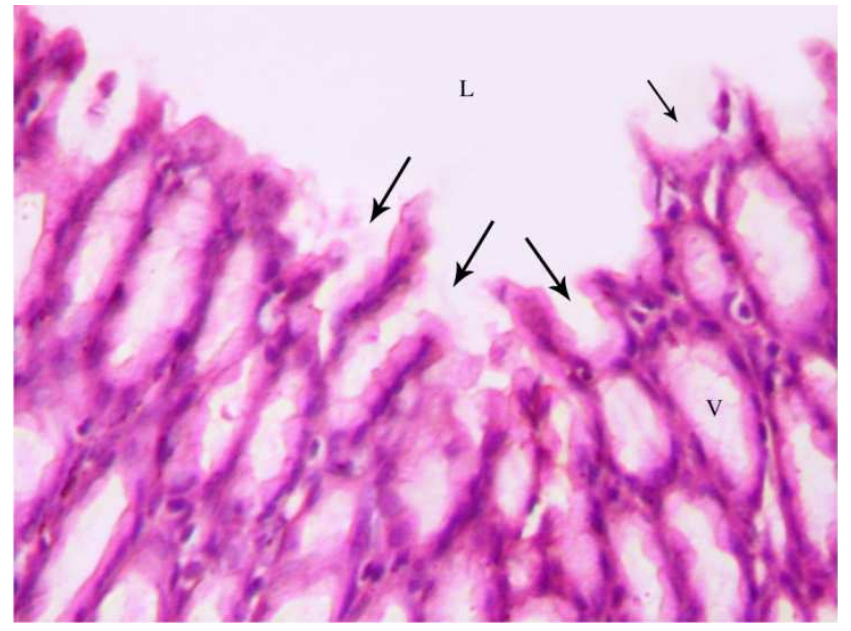

Fig. 27. A light photomicrograph of an adult rat fundic stomach treated with indomethacin and ascorbic acid, showing: Surface mucous cells are partially vacuolated $(V)$ and degenerated (arrows). Notice, the lumen of the stomach (L). (Hx\&EX400). 


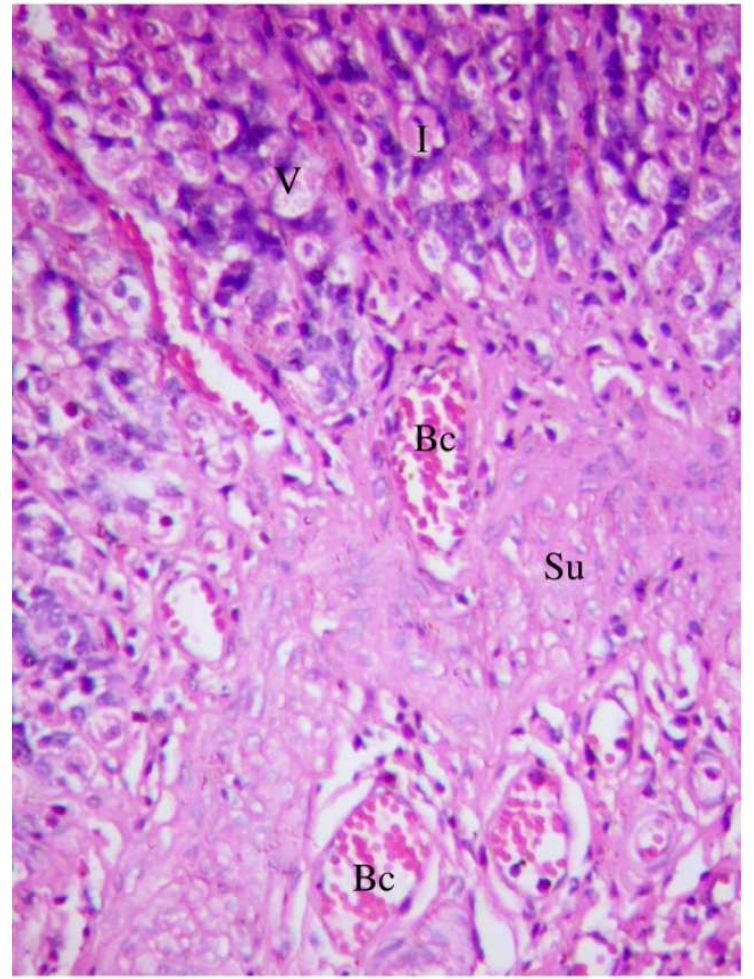

Fig. 28. A light photomicrograph of an adult rat fundic stomach treated with indomethacin and ascorbic acid, showing: Some parietal cells are vacuolated (V), while others are intact (I). Notice congested blood capillaries (Bc) in the submucosa (Su) of the stomach. (Hx \& E X200).

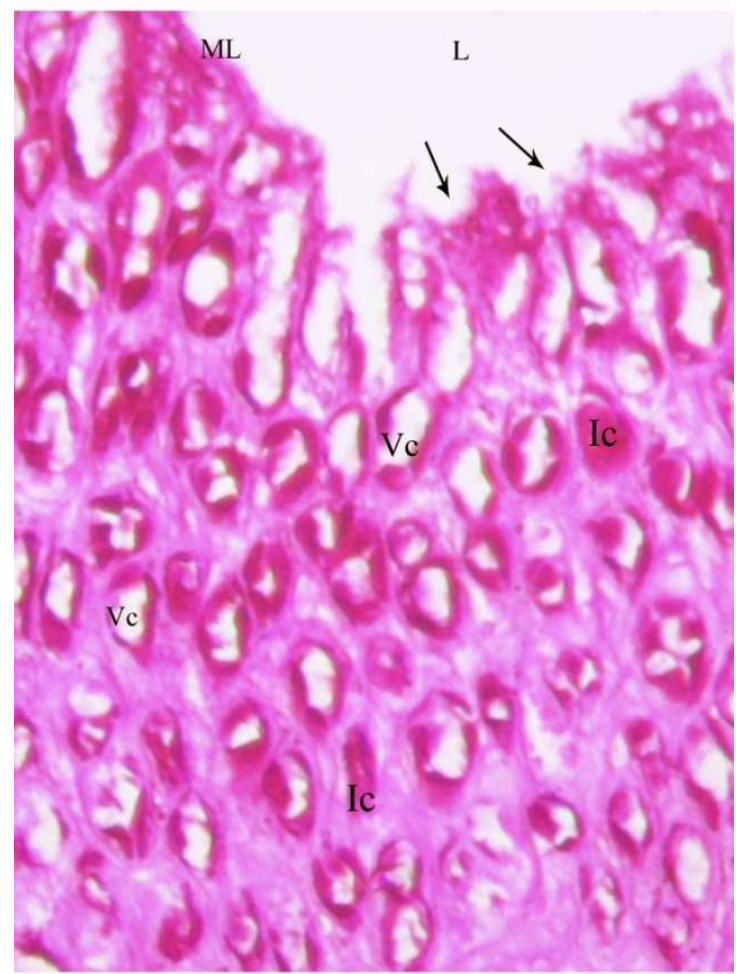

Fig. 29. A light photomicrograph of an adult rat fundic stomach treated with indomethacin and ascorbic acid, showing: Thin layer of mucin (ML) on the surface of gastric mucosa, when compared with the control group. Notice, small areas of surface mucosa not covered by mucin (arrows), some mucous secreting cells are intact (Ic) and other are vacuolated (Vc). Notice also, the lumen of the stomach (L). (P. A. S. X200).

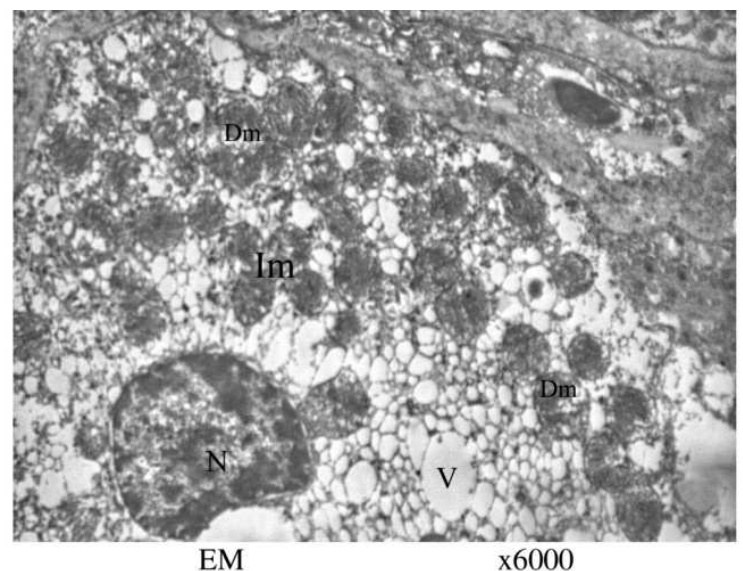

Fig. 30. An electron micrograph of an adult rat fundic mucosa treated with indomethacin and ascorbic acid, showing: Parietal cell having intact nucleus $(N)$, some mitochondria are partially intact (Im), while other are degenerated (Dm). The cytoplasm contains many vacuoles (V).(E. M X6000).

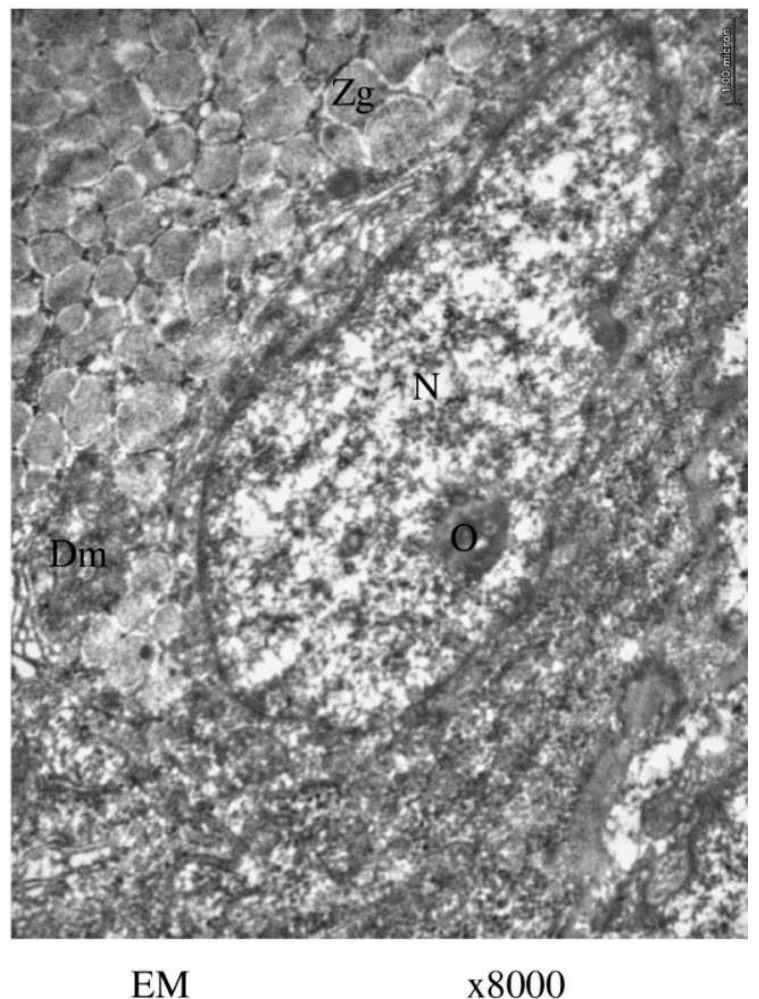

Fig. 31. An electron micrograph of an adult rat fundic mucosa treated with indomethacin and ascorbic acid, showing: chief cell with intact nucleus $(N)$, nucleolus (o), and apical translucent zymogenic granules (Zg). (E. MX 8000).

\subsection{Indomethacin Group Treated with Ranitidine}

By light microscopy, many parietal cells are intact, while others are vacuolated [Fig. 32]. The gastric glands are lined by intact cells in some areas, while other areas were lined by vacuolated cells. There was congestion of the blood capillaries in the muscuolaris mucosa [Fig. 33]. P. A. S. stain of the gastric mucosa shows thin layer of mucins secretion on the surface of the gastric mucosa. Most of the mucous secreting cells were vacuolated; few cells are filled with 
mucous secretion [Fig. 34].

By electron microscopy, parietal cell starts to appear normal, with normal nuclei and mitochondria, some cells contained multinuclei and some vacuoles [Fig. 35]. Chief cells contains intact nucleus and many translucent zymogenic granules, while other are dense in colour, with some degenerated mitochondria [Fig. 36].

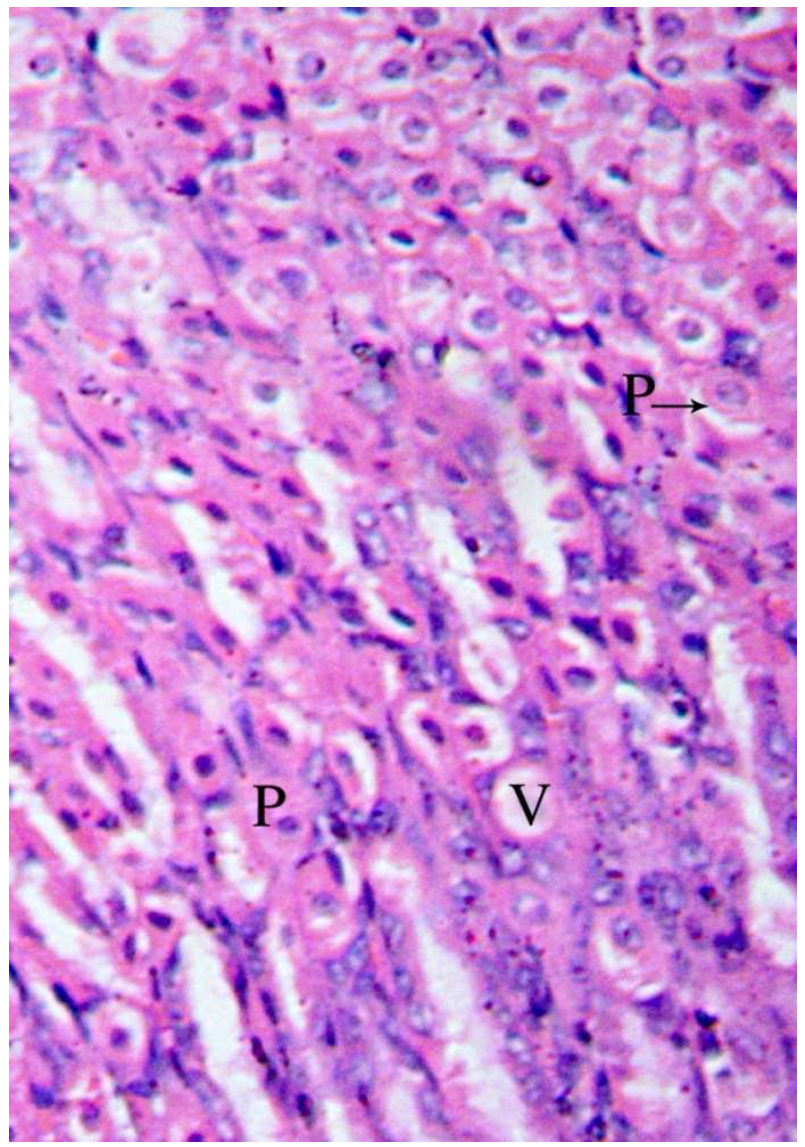

Fig. 32. A light photomicrograph of an adult rat fundic stomach treated with indomethacin and ranitidine, showing: Many Parietal cells are intact $(P)$ while other cells are vacuolated (V). (Hx \& E X200).

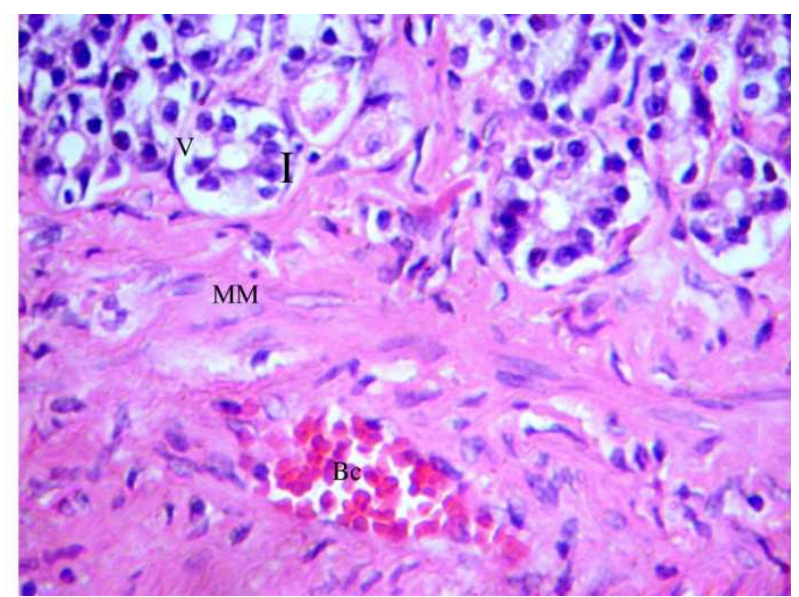

Fig. 33. A light photomicrograph of an adult rat fundic stomach treated with indomethacin and ranitidine, showing: The gastric glands are lined with intact cells (I) and vacuolated cells (V). Notice, congestion of blood capillaries (Bc), in the muscuolaris mucosae (MM). (Hx \& E X400).

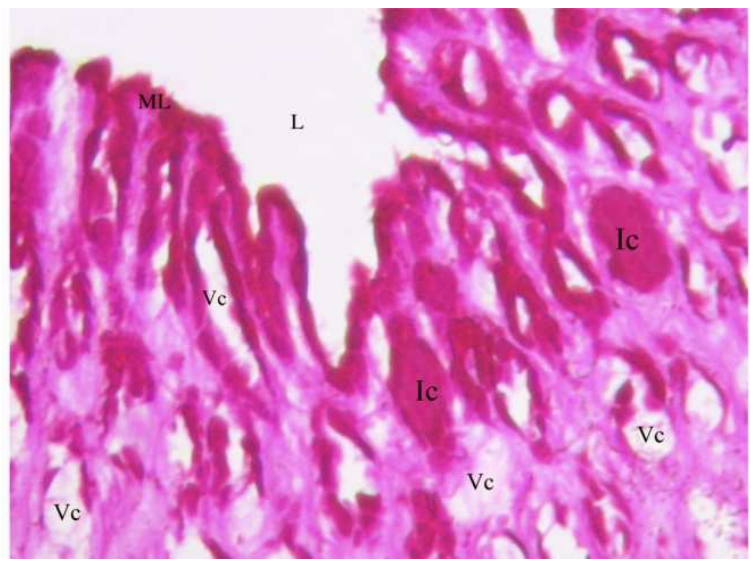

Fig. 34. A light photomicrograph of an adult rat fundic stomach treated with indomethacin and ranitidine, showing: Thin layer of mucin secretion (ML) on the surface of gastric mucosa. Most of the mucous secreting cells are vacuolated $(V c)$, few cells are filled with mucin (Ic). Notice, the lumen of the stomach (L). (P. A. S. X 200).

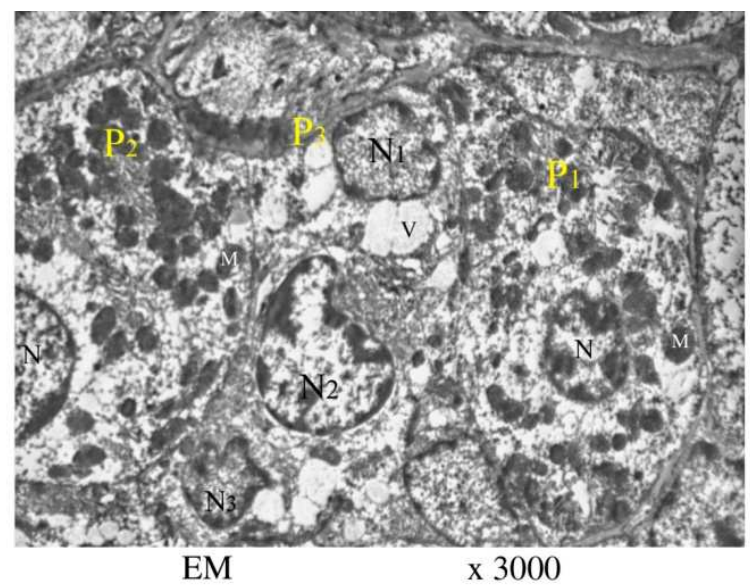

Fig. 35. An electron micrograph of an adult rat gastric mucosa treated with indomethacin and ranitidine, showing: Two intact parietal cells (P1 \& P2) with normal nuclei $(N)$ and mitochondria $(M)$. In between these two cells, another parietal cell (P3) contains multinuclei (N1, N2 \& N3) and some vacuoles $(V)$. (E. MX 3000).

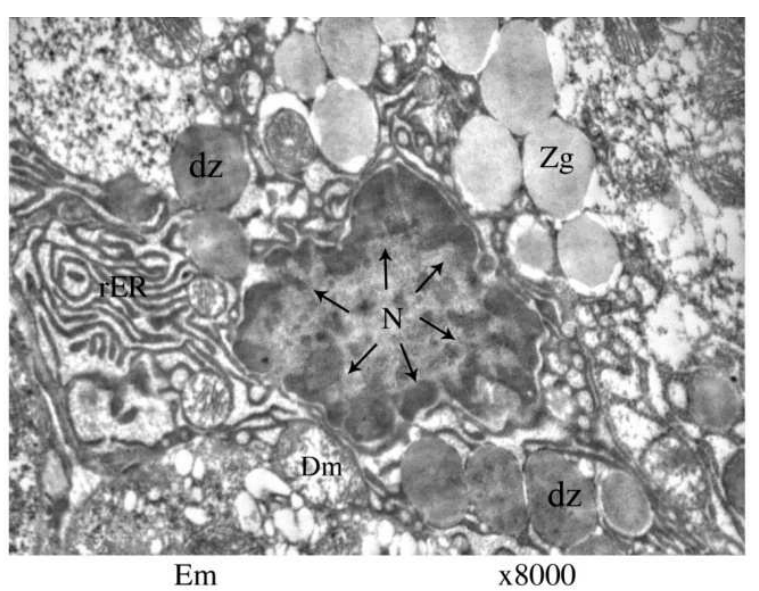

Fig. 36. An electron micrograph of an adult rat fundic mucosa treated with indomethacin and ranitidine, showing: Chief cells with irregular heterochromatic nucleus $(N)$ There are some translucent zymogenic granules $(\mathrm{Zg})$, and other dense granules (dz). Notice, the rough endoplasmic reticulum (rER), and degenerated mitochondria (Dm). (E. MX 8000). 


\subsection{Indomethacin Group Treated with both Ascorbic Acid and Ranitidine}

By light microscopy, parietal cells appear normal, with central deeply stained nucleus and eosinophilic cytoplasm. Some cells have vacuoles [Fig. 37]. P. A. S. stain of the gastric mucosa showed that the surface mucosa is covered by a well formed layer of mucin, with some intact mucous cells, while the others are vacuolated [Fig. 38].

By electron microscopy, the parietal cell restores its normal shape with normally appeared nucleus and mitochondria [Fig. 39]. The chief cells restored the normal shape of its nucleus and zymogenic granules [Fig. 40]. The mucous secreting cells have a lot of secretory granules which appeared normal [Fig. 41].

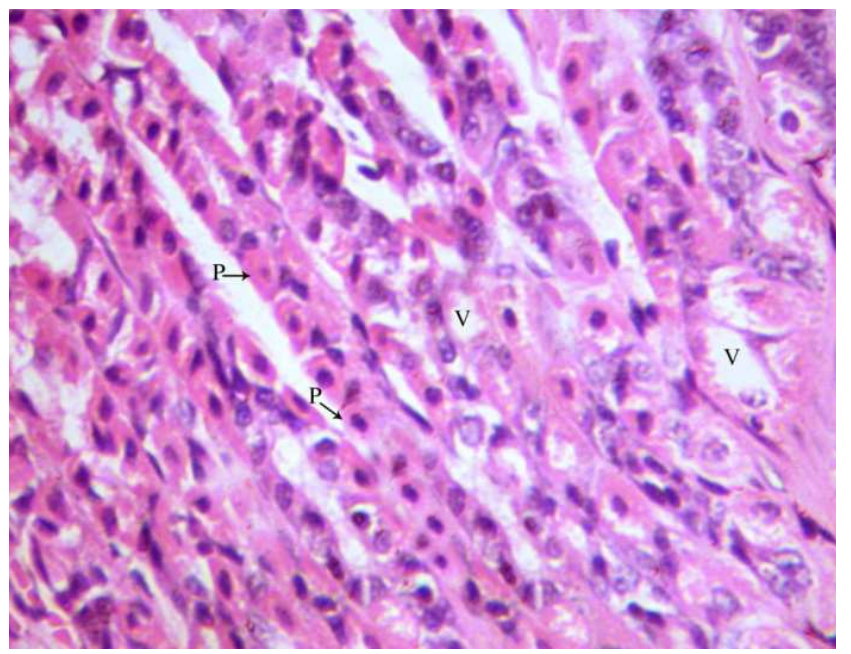

Fig. 37. A light photomicrograph of an adult rat fundic stomach treated with indomethacin, ascorbic acid, and ranitidine, showing: Intact parietal cells (P) with central deeply stained nucleus and eosinophilic cytoplasm. Notice, some parietal cells are vacuolated (V). (Hx \& E X200).

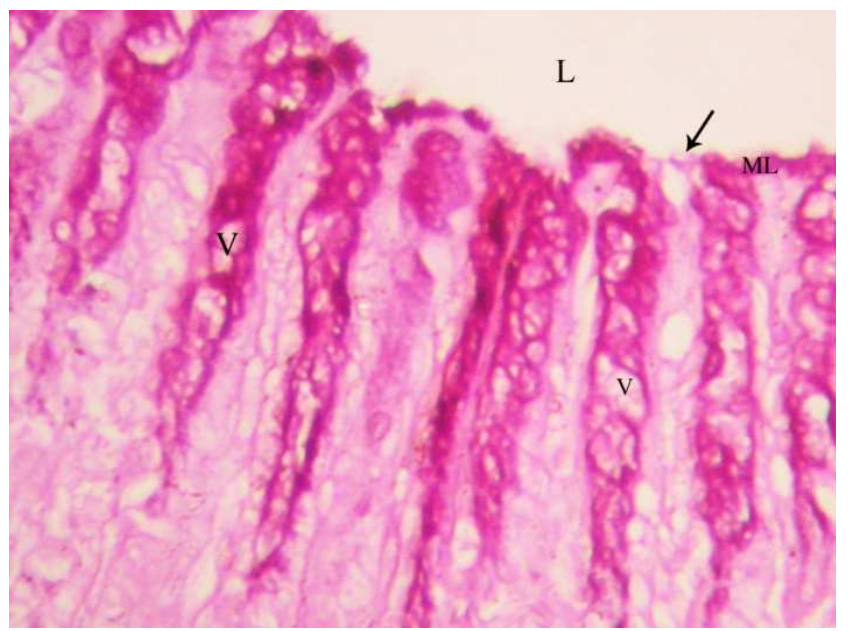

Fig. 38. A light photomicrograph of an adult rat fundic stomach treated with indomethacin, ascorbic acid, and ranitidine, showing: The surface mucosa is covered by thin layer of mucin (ML), some areas not covered with mucin (arrow). Notice, some vacuolated surface mucous cell (V), and the lumen of the stomach (L). ( $H x \& E X 400)$.

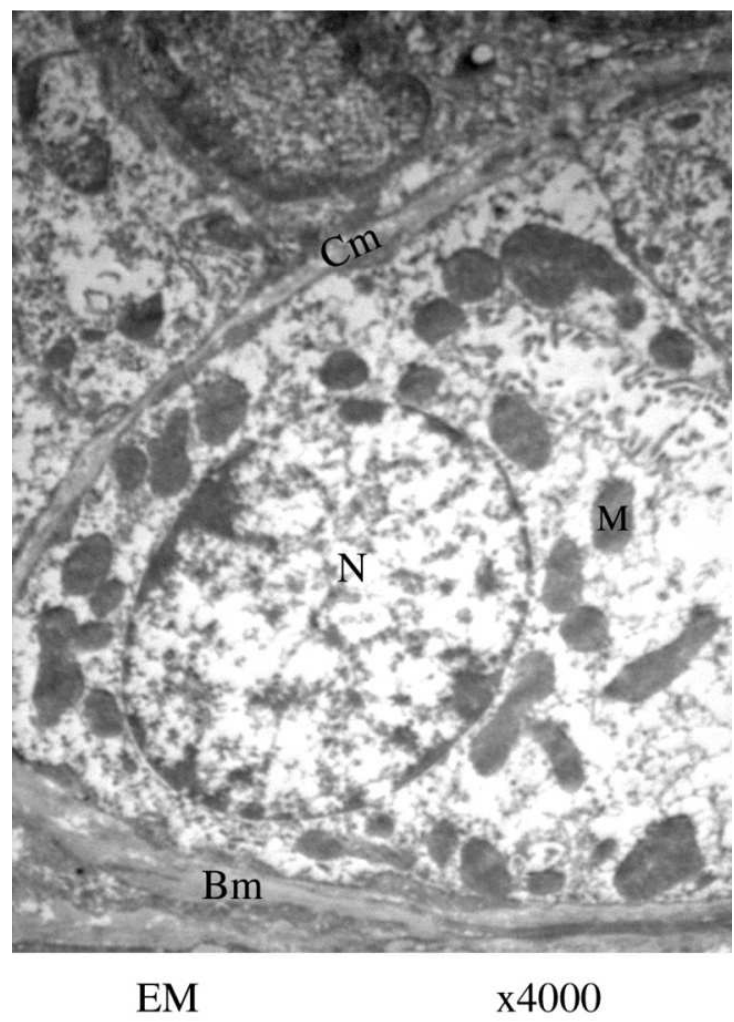

Fig. 39. An electron micrograph of an adult rat fundic mucosa treated with indomethacin, ascorbic acid, and ranitidine, showing: Normal shaped parietal cell attached to the basement membrane (Bm), with regular cell membrane (Cm), normal nucleus (N) and mitochondria (M).(E. MX4000).

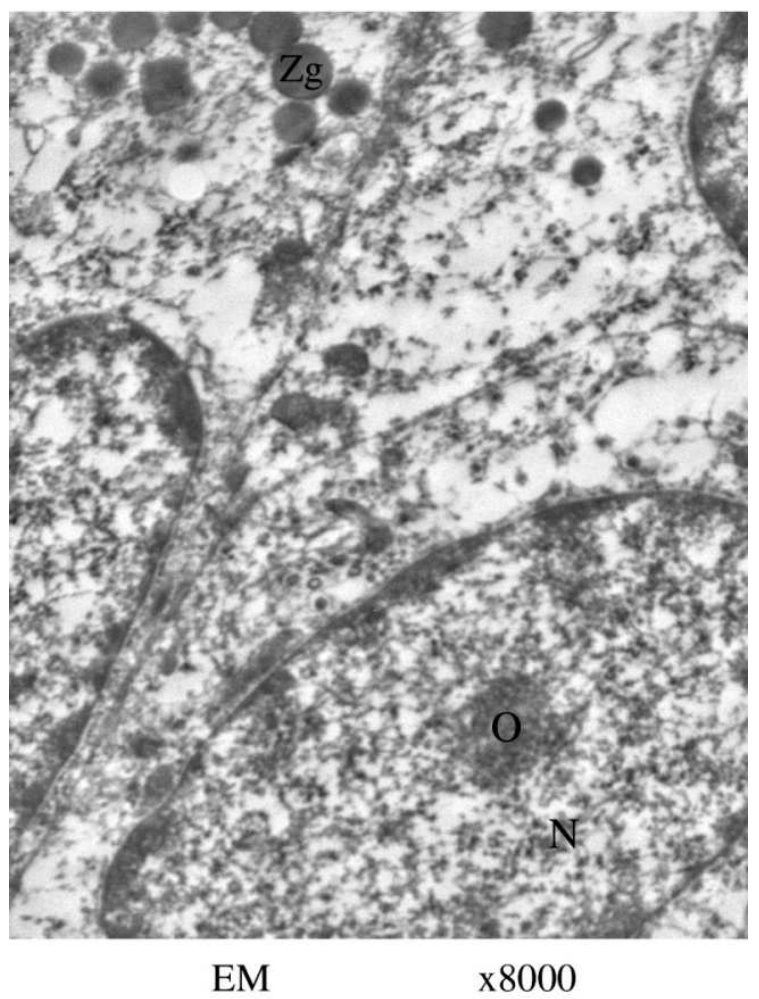

Fig. 40. An electron micrograph of an adult rat fundic mucosa treated with indomethacin, ascorbic acid, and ranitidine, showing: Chief cells with intact nucleus (N), nucleolus (O), and intact zymogenic granules $(\mathrm{Zg})$. (E. MX 8000). 


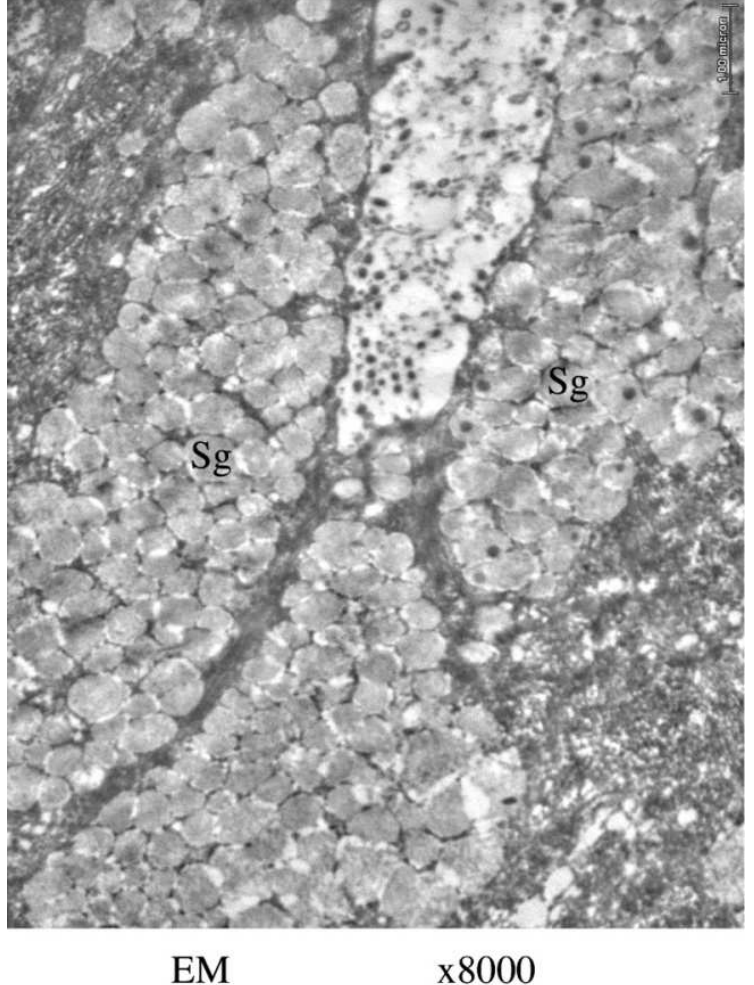

Fig. 41. An electron micrograph of an adult rat fundic mucosa treated with indomethacin, ascorbic acid, and ranitidine, showing: Intact mucous recreating cells with a lot of secretory granules (Sg). (E. MX 8000).

\section{Discussion}

The present study deals with the normal structure of the stomach wall of adult rat and the effects of Indomethacin on it. Also, this study evaluates the protective effects of ascorbic acid and ranitidine on the gastric mucosa.

In the present study, the microstructural examination of the stomach sections demonstrated that: The Indomethacininduced areas of focal degeneration in the gastric mucosa that becomes eroded, and ulcerated. So, the muscularis mucosae became exposed to the lumen of the stomach. These findings were similar to the results of [8] who observed massive necrosis, epithelial sloughing, and superficial ulcers after indomethacin administration. [9] Reported that, non-steroidal anti-inflammatory drugs (NSAIDs) induce stomach ulcers and bleeding by impairing the restitution process and inactivating several growth factors that are important in the mucosal defense and repair.

In the present study, there was infiltration of inflammatory cells in the lamina propria of the gastric mucosa, which runs parallel with the reports documented by [10] who reported that, there is heavy cellular infiltration observed in the ulcer beds of the fundic lamina propria. [11] Explained the presence of mononuclear cellular infiltration as the NSAIDs affected the intercellular junctions integrity and inhibited the production of the protective mucus layer. In doing so, the mucosa become exposed to the effect of acid and proteolytic enzymes with subsequent bacterial invasion of the mucosa. These bacteria were chemotactic for neutrophils, lymphocytes and macrophages. Moreover, [12] added that, polymorphonuclear leucocyte infiltration may be due to Helicobacter pylori infection which is related to NSAIDs ulcers, [13].

The present work showed congestion and dilatation of the blood vessels of the lamina propria and the submucosa of the gastric mucosa after indomethacin administration. These results were similar to that of [14] who mentioned that in case of gastric ulceration, the nearby blood vessels appeared dilated and congested.

In the present study, the thickness of the surface mucin layer was decreased when compared with that of the control group. These finding were in agreement with [15] who noticed depletion of the PAS stained granules together with a relatively thin mucous coat over the surface of the gastric mucin.

In this work, indomethacin produced electron microscopic changes in the parietal cells in the form of, degeneration of its nucleus and its mitochondria, with loss of its cristae. These results were in coincidence with the results of [16] who added that, the degeneration of the parietal cell following NSAIDs administration was time and dose dependent.

Indomethacin also made, the parietal cells appeared vacuolated with pyknotic nuclei and they were deprived from their mitochondrial content with dilatation of intracellular canaliculi. This was in accordance with [13]. [17] Reported that the vacuolations of parietal cells could be explained by the disruption and dilatation of their intracellular canaliculi together with increased number of microvesicles within their cytoplasm.

The chief cells had pyknotic nuclei, degenerated mitochondria, and dispersed endoplasmic reticulum. These finding were in agreement with [18] who postulated that, indomethacin's ability to cause cell damage may be related in part to its accumulation in these cells because of the phenomenon of ion trapping. Moreover, [19] suggested that, NSAIDs-induced impairment of the tight junction complex morphology and permeability between viable gastric mucosal epithelial cells may be a major contributing factor in the etiology of stomach disorder. The zymogenic granules of chief cell has a central deeper part with pale periphery, this was similar to the results of [20].

Many attempts were carried out by several authors to understand the mechanism through which the indomethacin exerted their effects on gastric mucosa. Some authors attributed these effects to suppression of endogenous prostaglandin synthesis, as [21] who hypothesized that the ulcerogenic action of indomethacin was due to the withdrawal of normal protection against ulcerations provided by prostaglandin in the gastric mucosa. Similarly, [22] reported that NSAIDs injured the gastric mucosa as a result of the action of the drug on the cyclooxygenase enzyme. This was in accordance with the findings of [23] who demonstrated that NSAIDs induced gastric mucosal injury results from direct topical injury and reduced mucosal resistance due to indirect or systemic inhibition of mucosal 
prostaglandin synthesis.

Also, [24 \& 25] reported that, indomethacin is a nonselective COX inhibitors (inhibit both COX-1 and COX-2), which cause more gastric damage than the other NSAIDs. Inhibition of COX-2 causes the anti-inflammatory effects and inhibition of COX-1 cause the gastric mucosal ulcer due to inhibition of cytoprotective prostaglandins in the gastric mucosa. Moreover, [26] concluded that indomethacin may delay the healing of gastric mucosal ulcers through inhibition of endogenous PG production and suppression of Hepatocyte growth factor (HGF).

Other authors concluded that indomethacin induced mucosal damage through vascular mechanisms. [27] Noticed that indomethacin may lead to fibrin deposition and arterial occlusion. [28] Added that NSAIDs affect the mucosal blood flow and mitochondrial oxidative phosphorylation. While, [29] concluded that, NSAIDs induce accumulation of oxygen free radicals secondary to reduction of mucosal blood flow.

Some other authors attributed the injurious effects of indomethacin to its direct action on mucosal cells such as [30] who postulated that, the ability of the indomethacin to cause epithelial damage might be related in part to its accumulation in these cells because of the phenomenon of ion trapping. Moreover, [31] suggested that indomethacin induces impairment of the tight junction complex morphology and permeability between viable gastric mucosal epithelial cells may be a major contributing factor in the etiology of stomach disorder.

Recent studies demonstrated that, one of the important mechanism by which indomethacin damage gastric mucosa is the increased production of reactive oxygen species (ROS) which has a critical role in the gastric ulceration process. It damages membrane proteins by causing lipid peroxidation in membranes by attacking unsaturated fatty acids. The damage to membrane proteins decreases the membrane's permeability, the activities of enzymes and receptors and the activation of inflammatory cells [32 \& 33].

The present study revealed that, pretreatment with ascorbic acid, ranitidine, or both, protect the gastric mucosa from the dangerous effect of indomethacin. They also protected the parietal and chief cells as well as the enteroendocrine cells except for some ulcerative areas and cellular infiltration of some rats. These results were in line with [5] who reported that, ascorbic acid, ranitidine, or both reduced the development of indomethacin-induced gastric damage.

Vitamin $\mathrm{C}$ is the most important water soluble biological antioxidant, it can scavenge the reactive oxygen species (ROS) e.g. hydrogen peroxide $(\mathrm{H} 2 \mathrm{O} 2)$ and the superoxide radical, which shown to play a critical role in the gastric ulceration process [34]. Also, ascorbic acid attenuates the deleterious effect of indomethacin on ulcer healing due to its anti-oxidant activity by mechanism involving preservation of gastric microcirculation, attenuation of lipid peroxidation and release of proinflammatory cytokines [35].

Administration of both indomethacin and vitamin $\mathrm{c}$ induce less gastric mucosal damage due to the increase in expression and activity of hemeoxygenase-1(HO-1). HO-1 plays an important role in gastric protection against indomethacin, by making cells more resistant to apoptotic death [36]. Ascorbic acid and ranitidine were found to increase group of enzymes e.g. glutathione, Superoxide dismutase, glutathione peroxidase, and glutathione S-transferase, which decreased in case of indomethacin administration and founded to play a role in gastric ulceration process [32].

\section{Conclusion}

The toxic effects of the indomethacin on the stomach, was reduced by the administration of vitamin c. Also, the use of ranitidine ameliorated the mucosal gastric injury induced by indomethacin. However, combination of both ascorbic acid and ranitidine was better in the treatment of indomethacin induced gastric injuries.

\section{References}

[1] Takeuchi K, Abe K, Yasuima M, Sato M, Tanno M, Suto K, Yoshinaga K. (1991): No adverse effect of non-steroidal antiinflammatory drugs, sulindac and diclofenac sodium on blood pressure control with a calcium antagonist, nifedipine. in elderly hypertensive patients. Res Commum Chem Pathol Pharmacol. 74: 141-152.

[2] Miller TA (1983): Protective effect of prostaglandins against gastric mucosal damage. Current knowledge and proposed mechanisms. Amj physiol 245: 601-623.

[3] Miura T, Muraoka S, Fujimoto Y (2002): Lipid peroxidation induced by indomethacin with horseradish peroxidase and hydrogen peroxide. Involvement of indomethacin radicals. Biochem Pharmacol, 63: 2069-2074.

[4] Saeidnia S. \& Abdollahi M. (2013): Toxicological and pharmacological concerns on oxidative stress and related diseases. Toxicol Appl Pharmacol. 273: 442-455.

[5] Murat, K., Halit, I, Fehmi, O (2008): Gastroprotective and Anti-oxidative Properties of Ascorbic Acid on Indomethacininduced Gastric Injuries in Rats. Biol Trace Elem Res, 126: 222-236.

[6] Smith SM, Kvietys PR. (1988): Gastric ulcers. Role of oxygen radicals. Crit Care Med 16: 892-898.

[7] Murat K, Halit I, Odabasoglu F (2008): Gastroprotective and anti-oxidative properties of ascorbic acid on indomethacininduced injuries in rats. Biol trace Elem Res. 126: 222-236.

[8] Barnett K, Bell CJ, Mc Knight W, Dicay M, Sharkey KA, Wallace JL. (2000): Role of cyclooxygenase-2 in modulating gastric acid secretion in the normal and inflamed rat stomach. Am J Physiol Gastrointest Liver Physiol. 279: P. 1292-1297.

[9] Wallace, J. L. (2000): How do NSAIDs cause ulcer disease Baillieres best Pract Res Clin Gasteroenterol 14: 147-159.

[10] Shiotani A, Yamaoka Y, El-Ziamaity HM, Saeed MA, Qureshi WA, Graham DY. (2002): NSAID gastric ulceration: Predictive value of gastric $\mathrm{PH}$, mucosal density of polymorphonuclear leukocyte, or levels of IL-8 nitrite. Dig Dis Sci. 47: 38-43. 
[11] Meyer RD, Mc Ginley D, Posalaky Z. (1986): Effects of aspirin on tight junction structure of the canine gastric mucosa. Gastroenterology. 91: 351-359.

[12] Caselli M, Ruina M, La Corte R, Trevisani L, Sartori S, Dentale A, Gaudenzi P, Trotta F, Alvisi V. (1996): Ultrastructural damage of gastric epithelium in patients taking NSAIDs. Ital. j. Gastrroenterol. 4: 16-18.

[13] Palacios-Espinosa JF, Arroyo-Garcia O., Garcia-Valencia G., Linares E., Bye R., Romero I. (2014): Evidence of the antiHelicobacter Pylori, gastroprotective and anti-inflammatory activities of Cuphea aequipetala infusion. J Ethnopharmacol. 151: $990-998$

[14] Bhandare P, Diniz-D, Souza R, and Mainker A, Dhume V. (1990): Protective effect of propranolol on ethanol-induced gastric lesions in mice. Eur J Pharmacol. 191: 167-172.

[15] Ribeiro AQ, Sevalho G, Cesar CC. (2006): The use of nonsteroidal anti-inflammatory drugs and the occurrence of gastric lesions among patients undergoing upper endoscopy in a university hospital in Brazil. Clinics. 16: 409-416.

[16] Rainsford KD, and Brune K. (1978): Selective cytotoxic actions of aspirin on parietal cells: A principal factor in the early stages of aspirin-induced gastric damage. Arch Toxicol. 27: $143-150$.

[17] Rainsford KD. (1986): Structural damage and changes in eicosanoid metabolites in the gastric mucosa of rats and pigs induced by anti-inflammatory drugs of varying ulcerogenisity. Int. Int J Tissue React. 8: 1-14.

[18] Tamura T, Yokoyama T, Ohmori K. (2001): Effects of diacerein on indomethacin-induced gastric ulceration. Pharmacol. 63: 228-233.

[19] Polat B, Albayrak Y, Suleyman B, Dursun H, Odabasoglu F, Yigiter M, Halici Z, Suleyman H. (2011): Antiulcerative effect of dexamedetomidine on indomethacin-induced gastric ulcer in rats. Pharmacol Rep. 63: 518-526.

[20] Adhikary B, Yadawy SK, Roy k, Bandyopadhyay SK, Chattopadhyay S. (2011): Black tea and theaflavins assist healing of indomethacin-induced gastric ulceration in mice by antioxidative action. Alternat Med. 25: 546-560.

[21] Sagar V, and Ahamed RN. (1999): Gastric mucosal cellular changes induced by indomethacin (NSAID) in male albino rats. Indian J. Exp Biol. 37: 365-369.

[22] Godessart N, Salcedo C, Fernandez AG, Palacios JM. (1999): Role of Cox-2 inhibition on the formation and healing of gastric ulcers induced by indomethacin in the rat. Adv Exp Med Biol. 469: 157-163.

[23] Kimmey MB. (1992): NSAID, ulcers, and prostaglandins. J Rheumatol Suppl. 36: 68-73.

[24] Suleyman H, Altinkaynak K, Gocer F, and Maras A, Akcay F, Onyk MD, Gepdiremen A. (2002): effect of nimesulide on the indomethacin-and ibuprofen-induced ulcer in rat gastric tissue. Pol J Pharmacol. 54: 255-259.
[25] Bambo H, Ota S, and Kato A, Matsuzaki F. (1998): Nonsteroidal anti-inflammatory drugs may delay the repair of gastric mucosa by suppressing prostaglandin-mediated increase of hepatocyte growth factor production. Biochem Biophys Res Commun. 245: 567-571.

[26] Erkinet B, Dokmeci D, and Altaner S, Turan FN. (2006): Gastroprotective effect of L-Carnitine on indomethacininduced gastric mucosal injury in rats: a preliminary study. Folia Med. 48: 86-89.

[27] Hawkey CJ. (1996): Quality of life in users of non-steroidal anti-inflammatory drugs. Gastroenterol Suppl. 221: 23-24.

[28] Wallace JL. (1997): Non-steroidal anti-inflammatory drugs and gastroenteropathy: the second handered years. Gastroenterology. 112: 1000-1016.

[29] Somasundaram S, Hayllar H, Rafi S, Wrigglesworth JM, Macpherson AJ, Bjarnason I. (1995): The biochemical basis of non-steroidal anti-inflammatory drug-induced damage to the gastrointestinal tract: a review and a hypothesis. Scand J Gastroenterol. 30: 289-299.

[30] Ohkawara T, Takeda H, Ohnishi S, Kato M, and Nishihira J, Asaka M. (2010): Macrophage migration inhibitory factor contributes to development of non-steroidal anti-inflammatory drugs-induced gastric injury in mice. Int Immunopharmacol. 11: 418-423.

[31] Pohle T, Badker JC, Markmann A. and Domschke W. (2001): Aspirin effects on gastric epithelial cell proliferation and cytokine expression. Microsc Res Tech. 53: 354-9.

[32] Nam JH, Kim IK, Lee MR, Hong SJ, and Ahn JH, (2012): Free radicals enzymatically triggered by Clonorchissinensis excretory-secretory products cause NF-KB-mediated inflammation in human cholangiocarcinoma cells. Int $\mathrm{J}$ Parasitol. 42: 103-113.

[33] Fiorucci S, Antonelli E, Morelli A. (2001): Mechanism of non-steroidal anti-inflammatory drugs-gastropathy.Dig. Dig Liver Dis. 2: 35-43.

[34] Ozdil S., Yanardag R., Koyuturk M., Bolkent S. and Arbak S. (2004): Protective effects of ascorbic acid, D1-alph-tocopherol acetate and sodium selenate on ethanol-induced gastric mucosal injury of rats. Biol Trace Element Res. 99: 173-189.

[35] Konturek PC, Kania J, Hahn EG, and Konturek JW. (2006): Ascorbic acid attenuates aspirin induced gastric damage Physiol Pharmacol. 5: 125-136.

[36] Zhu GH, Wong BC, Slosberg ED, Eggo MC, Ching CK, Yuen ST, Lai KC, Soh JW, and Weinstein IB, Lam SK. (2000): Overexpression suppresses indomethacin-induced apoptosis in gastric epithelial cells. Gastroenterology. 118: 507-514. 